\title{
EFEKTIVITAS FILTER SERPIHAN MARMER TERHADAP PENURUNAN KADAR BESI, MANGAN DAN MAGNESIUM PADA AIR SUMUR GALI
}

\author{
Nine Elissa Maharani ${ }^{1}$, Wartini $^{2}$ \\ ${ }^{1,2}$ Fakultas Kesehatan Masyarakat Universitas Veteran Bangun Nusantara Sukoharjo. \\ J1. Letjend. Sujono Humardani No 1 Kampus Jombor, Sukoharjo 57521 \\ Email : ${ }^{1}$ ninelisza_maharanie@yahoo.co.id, ${ }^{2}$ wartiniskm.msc@gmail.com
}

\begin{abstract}
ABSTRAK
Penelitian ini bertujuan untuk mengetahui efektifitas filter serpihan batu marmer dalam penurunan kadar besi, mangan dan magnesium pada air sumur gali di Desa Kaloran Kecamatan Wonogiri Kabupaten Wonogiri. Sampel diambil dari salah satu air sumur gali penduduk yang memiliki karakteristik berwana kekuningan kecoklatan, berbau besi dan agak amis, serta meninggalkan noda kuning pada bak mandi. Jenis penelitian ini adalah eksperimental dengan rancangan post test only control group design. Pada penelitian ini dilakukan dengan 3 perlakuan terhadap sampel air. Perlakuan I sebagai kontrol yaitu sampel air tidak diberikan perlakuan filter serpihan batu marmer. Perlakuan II sampel diberikan perlakuan berupa filter batu marmer dengan diameter $<1 \mathrm{~mm}$ dan yang ketiga sampel air sumur gali diberikan perlakuan dengan media filter batu marmer dengan diameter $\geq 1 \mathrm{~mm}$. Hasil dari ketiga jenis perlakuan tersebut kemudian dibandingkan dan dianalisis efektivitas filter batu marmer dalam menurukan kadar besi, mangan dan magnesium dalam air sumur gali. Data yang diperoleh dianalisis menggunakan One Way Anova dengan taraf 5\%. Hasil dari penelitian menunjukkan bahwa tidak ada efektivitas filter batu marmer dalam penurunan besi, mangan dan magnesium, dengan nilai $\mathrm{p}$ berturut-turut 0,$193 ; 0,930$ dan 0,729 .
\end{abstract}

Kata kunci : Air sumur gali, besi, magnesium, mangan, marmer.

\begin{abstract}
The purpose of the study was to determine the effectiveness of marble chile filter in decreasing levels of iron, manganese, and magnesium in well water dug in the village of Kaloran, Wonogiri District. The sample was taken from one of the well water that dug the population characteristic of yellowish-brownish, smelly iron and slightly fishy, and left the yellow stain on the bath. This type of research is experimental with post-test only control group design. In this study was conducted with 3 treatments of water samples. The treatment I as a control of water samples was not given the marble flake filter. Treatment II samples were given treatment in the form of marble stone filter with diameter $<1 \mathrm{~mm}$ and the third dug well water samples were given treatment with marble filter media with the diameter $\geq 1$ $\mathrm{mm}$. The results of the three types of treatment were then compared and analyzed the effectiveness of marble filter in reducing iron,
\end{abstract}


manganese, and magnesium in well water. The data obtained were analyzed using One Way Anova with 5\% level. The results of the study indicated that the use of marble filter was not effective in the reduction of iron, manganese, and magnesium, with p-values of 0.193 , 0.930 and 0.729 , respectively.

Keywords: Good water dug, iron, magnesium, manganese, marble.

\section{PENDAHULUAN}

Air yang dibutuhkan manusia, baik secara kualitas maupun kuantitas untuk memenuhi kebutuhan hidupnya, seperti untuk air minum, pengolahan makanan, pertanian, industri, perikanan, rekreasi dan olah raga maupun untuk pemenuhan lainnya, air yang tersedia seharusnya memenuhi persyaratan kesehatan (Rahayu, 2004). Menurut riset kesehatan dasar tahun 2013 menunjukkan bahwa jenis sumber air untuk seluruh kebutuhan rumah tangga di Indonesia pada umumnya adalah sumur gali terlindung $(29,2 \%)$, sumur pompa $(24,1 \%)$, dan air ledeng/PDAM (19,7\%) (Kemenkes RI, 2013).

Masalah penyediaan air bersih menjadi salah satu prioritas dalam perbaikan derajat kesehatan masyarakat. Mengingat keberadaan air sangat vital dibutuhkan oleh makhluk hidup. Seiring meningktnya kepadatan penduduk dan pesatnya pembangunan maka kebutuhan airpun sangat meningkat. Banyak penduduk yang terpaksa memanfaatkan air yang kurang bagus kualitasnya. Hal ini akan berakibat kurang baik bagi kesehatan masyarakat pada jangka pendek. Contohnya diare, muntaber, kolera, tipus dan disentri. Bila air tanah tercemar kotoran, otomatis kuman-kuman tersebar ke sumber air yang dipakai untuk keperluan rumah tangga. Dalam jangka panjang air yang berkualtas kurang dapat mengakibatkan penyakit keropos tulang, korosi gigi, anemis dan kerusakan ginjal. Hal ini terjadi karena terdapatnya logamlogam yang bersifat toksik dan terjadi pengendapan pada ginjal (Kusnaedi, 2010).

Kualitas air sumur gali dapat tercemar disebabkan oleh efek samping aktifitas manusia (Marsono, 2009). Menurut Kep Menkes RI No 492/MENKES/PER/IV/2010 syarat fisik air tidak berwarna, berbau, berasa, dan tidak keruh. Syarat kimia air tidak mengandung logam, misal aluminium, timbal, besi dan mangan. Baku mutu besi yang diperbolehkan dalam air minum maksimal 0,3 mg/liter (Depkes RI, 2010). Kadar besi yang tinggi dalam air memberikan gangguan dalam sistem penyediaan air bersih. Kadar besi yang tinggi pada air dapat menimbulkan penyumbatan pada pipa, memberikan warna kuning kecoklatan pada air, meninggalkan noda kuning pada pakaian dan bak mandi. Kadar besi lebih dari 0,3 mg/liter jika dikonsumsi dalam jangka panjang menyebabkan kerusakan pada dinding usus, kerusakan hati, jika dipakai mandi bisa menyebabkan iritasi mata dan kulit (Sarudji, 2006).

Masalah yang paling menonjol pada air sumur adalah bau busuk atau warna kuning karat berbau logam. Di perkotaan umumnya, air berbau busuk karena tanahnya sudah banyak tercemar limbah. Secara alami warna kuning atau bau logam karena air banyak mengandung besi $(\mathrm{Fe})$, mangan $(\mathrm{Mg})$ dan aluminium (Al) atau logam lain yang membahayakan kesehatan. Untuk menurunkan kandungan besi perlu sistem pengolahan air skala rumah tangga. Cara yang paling sering dilakukan dengan filtrasi. Filtrasi dapat mengatasi kekeruhan serta menurunkan 
kandungan kation yang larut, terutama kadar besi $(\mathrm{Fe})$ dan mangan $(\mathrm{Mg})$ (Kusnaedi, 2010). Media yang sering digunakan pasir, ijuk, zeolit, dan karbon aktif atau arang tempurung kelapa. Batu marmer limbah dari pengrajin marmer merupakan serpihan yang mirip dengan butiran pasir, serpihan-serpihan batu marmer bisa dipakai untuk media filtrasi air bersih. Penggunaan bahan tersebut belum populer atau belum banyak digunakan sebagai media penyaringan untuk menggantikan peran media pasir untuk menurunkan kadar besi dan kadar bahan organik dalam air (Ismadi, 2000). Prinsip dasar filtrasi adalah penyaringan secara fisik, kimia, biologi untuk memisahkan/menyaring partikel yang tidak terendapkan dalam proses sedimentasi media berpori. Proses filtrasi tersebut diperlukan untuk memisahkan flok-flok yang berukuran kecil/halus yang tidak dapat diendapkan sebesar 5 sampai $10 \%$. Proses yang terjadi pada filter ada beberapa macam yaitu: penyaringan mekanis, pengendapan dan aktivitas biologi (Asmadi dkk., 2010).

Media filter adalah bahan yang digunakan untuk filtrasi dan merupakan bagian dari filter yang terdiri dari material untuk mengisi atau yang tersusun di dalam filter, dimana media filter dipasang diantara aliran masuk (inlet) dan aliran keluar (outlet). Agar air dapat melewati media filter, maka media filter harus mempunyai sistem pori terbuka. Sistem pori itu disebut sebagai permukaan luar media filter (Asmadi dkk., 2010). Media filter yang sudah sering digunakan untuk menurunkan kekeruhan dan kadar besi, mangan maupun logam berat lainnya yang terkandung dalam air antara lain adalah zeolit, arang batok kelapa dan tawas. Ketiga media filter tersebut sudah sangat sering digunakan untuk menurunkan kekeruhan maupun menurunkan kadar logam besi yang terkandung dalam air. Media filter berupa limbah batu marmer sangat jarang digunakan dalam menurunkan kadar besi yang terdapat dalam air dan bahkan masyarakat juga belum familiar mengenai limbah marmer ini. Di Indonesia penyebaran marmer tersebut cukup banyak, seperti Lampung, Jawa Tengah, Jawa Timur, Jawa Barat, Banten, Kalimantan, Sulawesi, dan Kupang dan Bangka (Supriyono, 2011).

Berdasarkan survei awal yang telah dilakukan, jumlah sumur gali yang ada di Desa Kaloran Wonogiri ada 26 buah dengan karakteristik air semuanya berwarna kuning kecoklatan, berbau agak amis seperti bau besi/logam, pada bak kamar mandi banyak meninggalkan noda kekuningan serta jika digunakan untuk mencuci kadang menyebabkan pakaian berwarna kekuningan juga. Penelitian ini bertujuan untuk mengetahui efektifitas filter serpihan batu marmer dalam penurunan kadar besi, mangan dan magnesium pada air sumur gali di Desa Kaloran Kecamatan Wonogiri Kabupaten Wonogiri.

\section{METODE PENELITIAN}

\section{Desain Penelitian dan Lokasi}

Penelitian yang dilakukan ini adalah jenis penelitian eksperiment dengan rancangan post test only control group design. Pada desain penelitian ini pengelompokkan anggota kelompok eksperimen dan kelompok kontrol dilakukan dengan cara random. Kemudian dilakukan pre test pada kedua kelompok tersebut dan diberikan perlakuan pada kelompok eksperimen, selanjutnya dilakukan post test pada kedua kelompok tersebut (Riyanto, 2011). Penelitian ini dilakukan pada air sumur gali di Desa Kaloran Wonogiri.

\section{Populasi dan Sampel}

Sumur gali yang ada di Kaloran Kabupaten Wonogiri sejumlah 26. Pada penelitian ini yang menjadi sampel adalah 
air sumur gali dengan karakteristik berbau amis, berbau karat/besi, meninggalkan noda pada kekuningan/kecoklatan pada dinding kamar mandi serta jika digunakan untuk mencuci meninggalkan noda pada baju. Dalam penelitian ini yang menjadi sampel air sumur gali adalah milik bapak Sumarlan. Sampel yang dibutuhkan 20 liter dan setiap perlakuan dibutuhkan lima liter air dan dilakukan tiga kali pengulangan.

\section{Instrumen}

1. Bahan :
a. air sumur gali
b. butiran/serpihan batu marmer 10 liter
c. reagen $\mathrm{Fe} 10 \mathrm{ml}$
d. aquades

2. Alat:
a. pipa PVC
b. Shock draf dalam 3/4", shock draf luar $3 / 4$
c. Tutup pipa PVC 4"
d. Kran 3/4"
e. Ember besar (tandon air)
f. Jerigen besar
g. Ember sedang
h. Botol $300 \mathrm{ml}$
i. Ayakan pasir
j. Pipa T 3/4"
k. Lem pipa PVC
1. Gergaji
m. Pisau
n. Perekat/selotip
o. Pencatat waktu/jam
p. Thermometer
q. Ph meter
r. Gelas ukur $1000 \mathrm{ml}$
s. Spektofotometer (Multi Direct Tintometer Lovibond)

\section{Pengumpulan Data, Prosedur dan Analisis Data}

Pengumpulan data pada penelitian ini setelah proses filtrasi selesai, botolbotol diberi label dikirim ke laboratorium untuk dianalisis kandungan besi kemudian dianalisis efektivitas penurunan kadar besi dalam air sumur gali. Penelitian ini akan dianalisis menggunakan uji one way anova dengan taraf signifikansi 5\%.

\section{HASIL DAN PEMBAHASAN}

Tabel 1. Hasil Pemeriksaan Kadar Besi (Fe) mg/l, Mn dan $\mathrm{NO}_{2}$ Setelah Perlakuan

\begin{tabular}{lccccccccc}
\hline \multirow{2}{*}{ Parameter } & \multicolumn{3}{c}{ Kontrol } & \multicolumn{4}{c}{$\mathbf{A}$} & \multicolumn{3}{c}{ B } \\
\cline { 2 - 10 } & $\mathbf{1}$ & $\mathbf{2}$ & $\mathbf{3}$ & $\mathbf{1}$ & $\mathbf{2}$ & $\mathbf{3}$ & $\mathbf{1}$ & $\mathbf{2}$ & $\mathbf{3}$ \\
\hline $\mathrm{Fe}$ & 0,08 & 0,05 & 0,07 & 0,07 & 0,06 & 0,07 & 0,10 & 0,08 & 0,05 \\
$\mathrm{Mn}$ & 0,03 & 0,07 & 0,11 & 0,11 & 0,11 & 0,12 & 0,07 & 0,10 & 0,10 \\
$\mathrm{NO}_{2}$ & 12,9 & 13,4 & 13,5 & 14,7 & 12,1 & 12,9 & 13,1 & 13,9 & 13,5 \\
\hline $\mathrm{A}$ & & &
\end{tabular}

A : filter serpihan marmer diameter $<1 \mathrm{~mm}$

B : filter serpihan marmer diameter $\geq 1 \mathrm{~mm}$

Kontrol : air sumur gali yang tidak mendapatkan perlakuan apapun

Dari Tabel 1 dapat diperoleh ratarata kadar besi dalam air sebelum ada perlakuan pada air sumur gali (kelompok kontrol) adalah $0,067 \mathrm{mg} / \mathrm{L}$. Pada kelompok kontrol rata-rata untuk pemeriksaan kadar mangan dalam air sumur gali adalah $0,07 \mathrm{mg} / \mathrm{L}$. Untuk $\mathrm{NO}_{2}$ rata-rata kadar dalam air sumur gali kelompok kontrol adalah 13,27 $\mathrm{mg} / \mathrm{L}$.
Setelah dilakukan proses filtrasi menggunakan media filter marmer dengan diameter $<1 \mathrm{~mm}$ didapat penurunan hasil filtrasi kadar besi dalam air pada perlakuan ke 1 dibandingkan perlakuan ke 2, kadar besi naik $0,01 \mathrm{mg} / \mathrm{liter}$ sedangkan pada perlakuan ke 3 kadar besi konstan yaitu tetap pada $0,07 \mathrm{mg} / \mathrm{L}$. Perlakuan filtrasi menggunakan diameter $<1 \mathrm{~mm}$ 
dilakukan pengulangan sebanyak $3 x$. Rata-rata kadar besi pada perlakuan dengan diameter $<1 \mathrm{~mm}$ adalah 0,067 $\mathrm{mg} / \mathrm{L}$. Pada perlakuan ketiga yaitu dengan diameter filter $\geq 1 \mathrm{~mm}$ kadar besi mengalami kenaikan pada perlakuan pertama dan kedua dibandingkan dengan kelompok kontrol. Rata-rata kadar besi pada perlakuan diameter $\geq 1 \mathrm{~mm}$ adalah 0,077 mg/L. Jadi pada serpihan marmer dengan diameter $<1 \mathrm{~mm}$ untuk filter air sumur gali rata-rata kadar besinya lebih rendah apabila dibanding dengan filter serpihan marmer dengan diameter $\geq 1 \mathrm{~mm}$.

Pada perlakukan dengan filter serpihan marmer $<1 \mathrm{~mm}$ didapatkan kadar mangan rata-rata dalam air sumur gali adalah 0, $11 \mathrm{mg} / \mathrm{L}$. Pada perlakuan dengan filter serpihan marmer dengan diameter $\geq 1 \mathrm{~mm}$ didapatkan rata-rata kadar mangan $0,27 \mathrm{mg} / \mathrm{L}$. Jadi diantara perlakuan terhadap air sumur gali dengan filter serpihan marmer diameter $<1 \mathrm{~mm}$ dengan serpihan marmer $\geq 1 \mathrm{~mm}$ terdapat penurunan kadar magaan $0,16 \mathrm{mg} / \mathrm{L}$.

Untuk hasil analisis kadar nitrit dalam air sumur gali didapatkan hasil ratarata kontrol 13,26 mg/L. Pada perlakuan dengan filter $<1 \mathrm{~mm}$ rata-rata kadar nitrit dalam air sumur gali adalah 13,23 mg/L. Pada perlakuan dengan filter diameter $\geq 1$ $\mathrm{mm}$ rata-rata kadar nitrit dalam air sumur gali adalah 13,5 mg/L. Hasil analisis ini sama dengan parameter besi dan mangan yaitu terjadi penurunan kadar nitrit dari dua filter serpihan marmer dengan diameter yang berbeda yaitu sebesar 0,27 $\mathrm{mg} / \mathrm{L}$.

\section{Analisis Bivariat}

Analisis bivariat dalam penelitian ini digunakan untuk mengetahui efektivitas filter serpihan batu marmer terhadap penurunan kadar besi pada air sumur gali.
Tabel 2. Efektivitas Media Filter Batu Marmer Terhadap Penurunan Kadar Besi

\begin{tabular}{cccc}
\hline \multirow{2}{*}{$\begin{array}{c}\text { Rata-rata } \\
\text { control } \\
(\mathbf{m g} / \mathbf{L})\end{array}$} & $\begin{array}{c}\text { Rata-rata kadar } \\
\text { besi setelah } \\
\text { perlakuan }(\mathbf{m g} / \mathbf{L})\end{array}$ & $\begin{array}{c}\text { Efektivitas } \\
\text { filter serpihan } \\
\text { marmer dari } \\
\text { dua diameter } \\
(\%)\end{array}$ \\
\hline 0,067 & $\mathbf{A}$ & $\mathbf{B}$ & \begin{tabular}{c} 
B $)$ \\
\hline
\end{tabular} \\
\cline { 2 - 3 }
\end{tabular}

Berdasarkan Tabel 2 menunjukkan hasil bahwa rata-rata filtrasi media batu marmer dengan diameter $<1 \mathrm{~mm}$, dari 0,067 $\mathrm{mg} / \mathrm{L}$ menjadi $0,067 \mathrm{mg} / \mathrm{L}$, dengan demikian dari kelompok kontrol dan serpihan filter batu marmer tidak terjadi penurunan kadar besi, tetapi dari perlakuan filterisasi menggunakan filter batu marmer dengan diameter $<1 \mathrm{~mm}$ dan filter batu marmer dengan diameter $\geq 1$ $\mathrm{mm}$ terdapat efektivitas penuruna kadar besi sebesar 12,98\%. Filtrasi adalah proses penghilangan partikel-partikel atau flok-flok halus yang lolos dari unit sedimentasi. Partikel-partikel tersebut akan bertahan pada media filtrasi selama air melewati media tersebut. Filtrasi diperlukan untuk menurunkan kadar besi, warna dan bau pada air (Kusnaedi, 2010).

Media filter batu marmer berfungsi untuk proses adsorbsi yaitu melekatnya partikel ion atom maupun molekul pada permukaan zat lain. Hal ini terjadi karena adanya kekuatan partikel koloid untuk menarik partikel yang lebih ringan karena tegangan permukaan koloid yang lebih tinggi sehingga apabila partikel menempel akan dipertahankan pada permukaannya.

Filter yang sering digunakan dalam filtrasi air antara lain adalah resin dan zeolit. Resin merupakan bahan sintetik yang berasal dari aneka ragam bahan alamiah maupun sintetik, organik maupun anorganik. Sedangkan zeolit merupakan suatu media yang mempunyai sifat kemampuan pertukaran ion, daya serap dan daya molekuler. Zeolit mengandung ion negatif sehingga mampu mengikat kation dalam air. Air yang dialirkan melalui zeolit maka kation di dalamnya 
akan terikat oleh zeolit (Titik Isdiana, 2011).

Dalam penelitian ini, fungsi zeolit dan resin digantikan oleh serpihan batu marmer dari limbah/ sisa pengrajin kijeng yang ada di wilayah Wonogiri kota. Ratarata kontrol (tanpa perlakuan) adalah $0,067 \mathrm{mg} / \mathrm{L}$. Filtrasi dengan media filter serpihan batu marmer dengan diameter < $1 \mathrm{~mm}$ dan pengulangan 3 kali didapatkan rata-rata hasil $0,067 \mathrm{mg} / \mathrm{l}$. Dari hasil tersebut maka tidak terjadi penurunan kadar besi dalam air sumur gali. Dalam proses ini waktu kontak yang diperlukan setiap perlakuan adalah 20 detik.

Kepmenkes RI. No. 492/ Menkes/ Per/IV/2010, yaitu baku mutu besi yang diperbolehkan dalam air minum maksimal adalah $0,3 \mathrm{mg} /$ liter. Besi dibutuhkan oleh tubuh untuk pembentukan hemoglobin dan tubuh manusia memerlukan zat besi dalam jumlah kecil (Slamet, 2007). Kadar besi yang tinggi dalam air menyebabkan gangguan pada sistem penyediaan air bersih, contohnya menyumbat pipa-pipa air, meninggalkan noda kuning pada pakaian dan bak mandi serta memberikan warna kuning pada air. Air sumur gali yang memiliki kandungan besi di atas 0,3 $\mathrm{mg} / \mathrm{L}$ apabila dikonsumsi masyarakat dalam jangka waktu yang panjang akan menyebabkan kerusakan pada dinding usus, kerusakan hati dan jika digunakan untuk mandi akan menyebabkan iritasi mata dan kulit, terutama bagi individu yang peka (Sarudji, 2006).

Tabel 3. Efektivitas Media Filter Batu Marmer Terhadap Penurunan Kadar Mangan dalam Air Sumur Gali

\begin{tabular}{|c|c|c|c|}
\hline \multirow{2}{*}{$\begin{array}{c}\text { Rata-rata } \\
\text { control } \\
(\mathrm{mg} / \mathrm{L})\end{array}$} & $\begin{array}{l}\text { Rata } \\
\text { man } \\
\text { perla }\end{array}$ & $\begin{array}{l}\text { adar } \\
\text { elah } \\
\text { mg/L) }\end{array}$ & \multirow{2}{*}{$\begin{array}{c}\text { Efektivitas } \\
\text { filter serpihan } \\
\text { marmer dari } \\
\text { dua diameter } \\
(\%)\end{array}$} \\
\hline & A & B & \\
\hline 0,07 & 0,11 & 0,27 & 59,25 \\
\hline
\end{tabular}

Berdasarkan Tabel 3 diketahui tidak terjadi penurunan kadar mangan dari kontrol sampai perlakuan dengan diameter $<1 \mathrm{~mm}$ maupun $\geq 1 \mathrm{~mm}$, tetapi dari filterisasi menggunakan batu marmer dengan diameter $<1 \mathrm{~mm}$ dan $\geq 1 \mathrm{~mm}$ terjadi penurunan kadar mangan dari 0,27 menjadi $0,11 \mathrm{mg} /$ liter sehingga terdapat efektivitas penurunan sebesar 59,25\%.

Tabel 4. Efektivitas Media Filter Batu Marmer Terhadap Penurunan Kadar Nitrit dalam Air Sumur Gali

\begin{tabular}{cccc}
\hline \multirow{2}{*}{$\begin{array}{c}\text { Rata-rata } \\
\text { control } \\
(\mathbf{m g} / \mathbf{l})\end{array}$} & $\begin{array}{c}\text { Rata-rata kadar } \\
\text { nitrit setelah } \\
\text { perlakuan }(\mathbf{m g} / \mathbf{l})\end{array}$ & $\begin{array}{c}\text { Efektivitas } \\
\text { filter serpihan } \\
\text { marmer dari } \\
\text { dua diameter } \\
(\%)\end{array}$ \\
\hline 13,26 & $\mathbf{A}$ & $\mathbf{B}$ & \begin{tabular}{c} 
B \\
\cline { 2 - 3 }
\end{tabular} \\
\hline
\end{tabular}

Berdasarkan Tabel 4 terdapat penurunan kadar nitrit dalam air sumur gali dari kelompok kontrol rata-rata 13,26 $\mathrm{mg} /$ liter menjadi $13,23 \mathrm{mg} / \mathrm{liter}$ untuk media filter batu marmer dengan diameter $<1 \mathrm{~mm}$, sehingga pada diameter $<1 \mathrm{~mm}$ tersebut terdapat efektivitas penurunan nitrit sebesar $0,22 \%$. Pada perlakuan filterisasi dengan diameter $\geq 1 \mathrm{~mm}$ tidak terjadi penurunan kadar nitrit tetapi malah terjadi kenaikan kadar nitrit dari 13,26 mg/liter menjadi 13,5 mg/liter. Dari dua diameter filter tersebut, pada diameter yang lebih kecil yaitu $<1 \mathrm{~mm}$ kadar nitrit lebih rendah bila dibandingkan dengan filter diameter $\geq 1 \mathrm{~mm}$ yaitu dari kadar 13,23 mg/liter menjadi 13,5 mg/liter. Dari hasil analisis tersebut terdapat efektivitas penurunan kadar nitrit sebesar 2\% pada kondisi dua diameter yang berbeda.

\section{Efektivitas Filter Serpihan Batu Marmer Berdasarkan Diameternya}

$$
\begin{aligned}
& \mathrm{P}=\frac{a-b}{a} \times 100 \% \\
& \mathrm{P}=\text { efektivitas } \\
& \mathrm{a}=\text { rata-rata kadar besi dalam air diberi } \\
& \text { perlakuan filtrasi } \geq 1 \mathrm{~mm} \\
& \mathrm{~b}=\text { rata-rata kadar besi dalam air setelah } \\
& \text { diberi perlakuan filtrasi }<1 \mathrm{~mm}
\end{aligned}
$$


1. Efektivitas filter serpihan marmer dalam penurunan kadar besi

$$
\begin{aligned}
\mathrm{P} & =\frac{0,077-0,067}{0,077} \times 100 \% \\
& =12,98 \%
\end{aligned}
$$

2. Efektivitas filter serpihan marmer terhadap penurunan kadar Mangan

$$
\begin{aligned}
P & =\frac{0,27-0,11}{0,27} \times 100 \% \\
& =59,25 \%
\end{aligned}
$$

3. Efektivitas filter serpihan marmer terhadap penurunan kadar Nitrit

$$
\begin{aligned}
\mathrm{P} & =\frac{13_{x} 5-13_{2} 23}{13_{x} 5} \times 100 \% \\
& =2 \%
\end{aligned}
$$

4. Efektivitas filter serpihan marmer terhadap penurunan kadar Nitrit dengan diameter $<1 \mathrm{~mm}$

$$
\begin{aligned}
\mathrm{P} & =\frac{13,26-13,23}{13,26} \times 100 \% \\
& =0,22 \%
\end{aligned}
$$

Tabel 5. Hasil Uji Anova Kadar Besi dalam Air Sumur Gali

\begin{tabular}{lccccc}
\hline & Sum of Squares & Df & Mean Square & F & Sig. \\
\hline Between Groups & .000 & 2 & .000 & .333 & .729 \\
Within Groups & .002 & 6 & .000 & & \\
\hline Total & .002 & 8 & & & \\
\hline
\end{tabular}

Berdasarkan Tabel 5 diketahui tidak ada efektivitas penurunan filter bahwa nilai $p$ value 0,729 lebih besar dari serpihan batu marmer terhadap penurunan nilai $\alpha 0,05$ sehingga Ho diterima artinya kadar besi dalam air sumur gali.

Tabel 6. Hasil Uji Anova Kadar Mangan dalam Air Sumur Gali

\begin{tabular}{lccccc}
\hline & Sum of Squares & Df & Mean Square & F & Sig. \\
\hline Between Groups & .003 & 2 & .001 & 2.190 & .193 \\
Within Groups & .004 & 6 & .001 & & \\
\hline Total & .007 & 8 & & & \\
\hline
\end{tabular}

Berdasarkan Tabel 6 dapat dilihat sehingga dengan demikian dapat bahwa hasil uji anova satu jalan disimpulkan bahwa tidak ada efekivitas didapatkan nilai $p$ value 0,193 , dimana penurunan kadar mangan oleh filter nilai tersebut lebih besar dari nilai $\alpha 0,05$ serpihan marmer.

Tabel 7. Hasil Uji Anova Satu Jalan Kadar Nitrit Dalam Sumur Gali

\begin{tabular}{lccccc}
\hline & Sum of Squares & Df & Mean Square & F & Sig. \\
\hline Between Groups & .106 & 2 & .053 & .074 & .930 \\
Within Groups & 4.289 & 6 & .715 & & \\
\hline Total & 4.394 & 8 & & & \\
\hline
\end{tabular}

Berdasarkan Tabel 7 dapat dilihat bahwa nilai $p$ value adalah $0.930>$ nilai $\alpha$ 0,05 sehingga Ho diterima artinya tidak ada efektivitas filter batu marmer terhadap penurunan kadar nitrit pada air sumur gali.

\section{KESIMPULAN}

Tidak ada efektivitas media filter serpihan batu marmer terhadap penurunan kadar besi, mangan dan magnesium (nitrit) pada air sumur gali. 


\section{DAFTAR PUSTAKA}

Asmadi, Khayan, Heru Subaris., 2010, Teknologi Pengolahan Air Minum, Gosyen Publishing, Yogyakarta.

Depkes RI., 2010, Permenkes RI No. 492/Menkes/PER/IV/2010., Persyaratan Kualitas Air Minum.

Ismadi., 2000, Uji Beda Efektivitas Media Batu Marmer dan Zeolit dalam Menurunkan Kesadahan, Klaten.

Kemenkes RI., 2003, Riskesdas Tahun 2013, Depkes RI, Jakarta.

Kusnaedi., 2010, Mengolah Air Kotor Untuk Air Minum, Panebar Swadaya, Jakarta.

Marsono., 2009, Faktor-Faktor yang Berhubungan Dengan Kualitas Bakteriologis Air Sumur Gali di Permukiman, Tesis, Program Pascasarjana UNDIP, Semarang.

Rahayu, T., 2004, Karakteristik Air Sumur Dangkal di Wilayah Kartasura dan Upaya Penjernihannya, Jurnal Penelitian Sains \& Teknologi, Vol. 5, No. 2, 2004: 104-1.

Riyanto, A., 2011, Aplikasi Metodologi Penelitian Kesehatan, Nuha Medika, Yogyakarta.

Sarudji, D., 2006, Kesehatan Lingkungan, Media Ilmu, Sidoarjo.

Slamet, JS., 2007, Kesehatan Lingkungan, Gajah Mada University Press, Yogyakarta.

Supriyono., 2011, Kemampuan Media Filtrasi Berupa Butiran Serbuk Batu Marmer Dalam Menurunkan Kekeruhan dan Permanganate Volume Dalam Air, Institut Teknologi Adhi Tama, Surabaya.

Titik Isdiana., 2011, Pengaruh Berbagai Kombinasi Ketebalan Media Filter Pasir dan Zeolit Terhadap Penurunan Kadar Besi dan Mangan Pada Sumur Perum Nilasari Pabelan Kartasura, Universitas Muhammadiyah Surakarta, Surakarta. 